\title{
BDA blasts GDC as ARF remains unchanged during pandemic
}

The BDA has lamented the General Dental Council's decision that it will not make changes to the Annual Retention Fee (ARF) levels or introduce an emergency payment scheme to allow registrants to pay by instalments.

With the profession now facing grave financial uncertainty the regulator's clear demonstration of inflexibility to colleagues, some of whom have seen their incomes fall to zero, has been widely condemned by the profession it seeks to regulate.

The GDC retains a budget operating surplus and significant reserves.

BDA Chair Mick Armstrong said: 'Despite recognising the dire financial circumstances in which many practices and individual registrants find themselves, the GDC has not seen fit to provide even token support, citing no fundamental change to the work it does and the little financial impact the move would have on registrants.

'Greater transparency into the reasoning behind this decision would have been the very least response registrants should have received.

'But the message we are left with is 'we need all the money and whatever we could do won't really help you much".

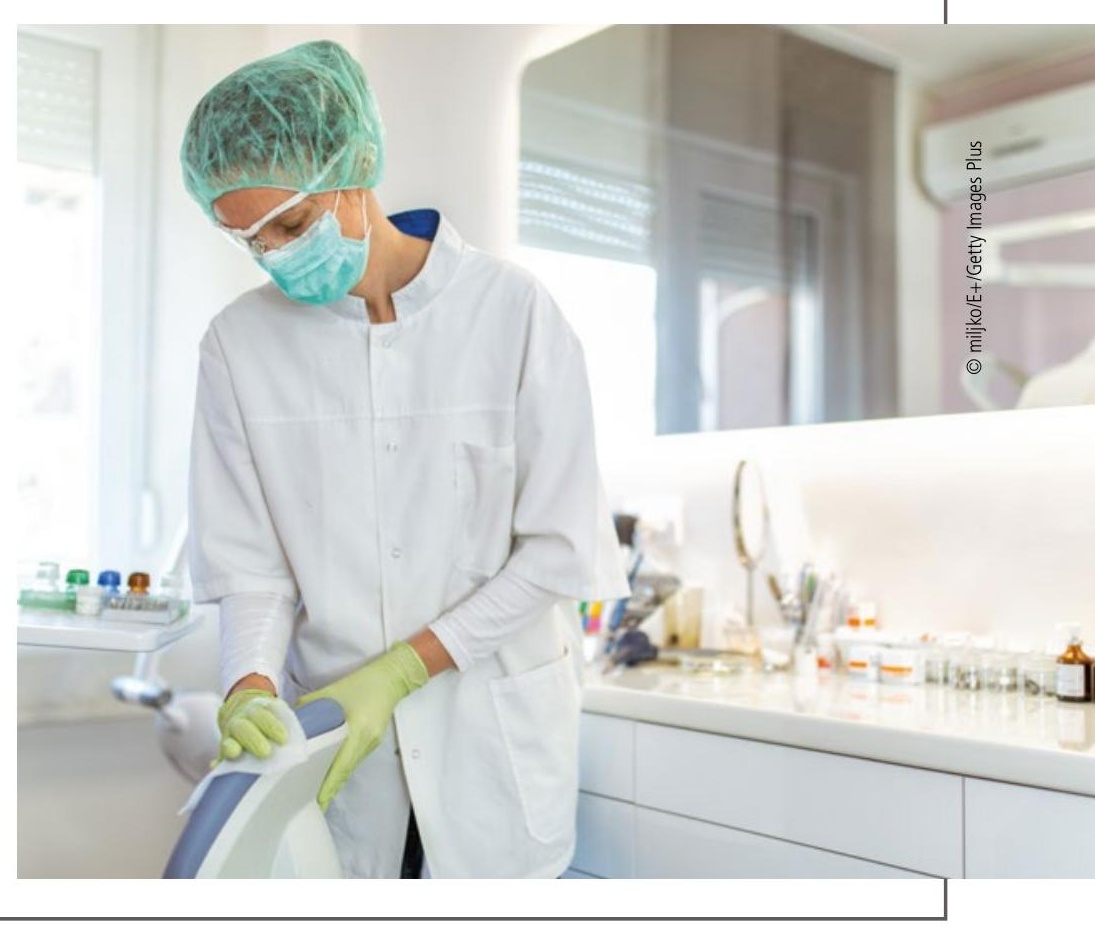

\section{Our CPD Hub makes CPD simple}

\author{
Earn, track and manage your CPD
}

Access over 90 hours of verifiable CPD a year - wherever you are

- British Dental Journal - 48 HOURS

- BDJ In Practice - 12 HOURS

- Data Protection Officer training - 5 HOURS

- Child protection and the dental team - 3 HOURS

- Oral cancer recognition toolkit - 3 HOURS

- BDA's collection of eBooks - 30 HOURS

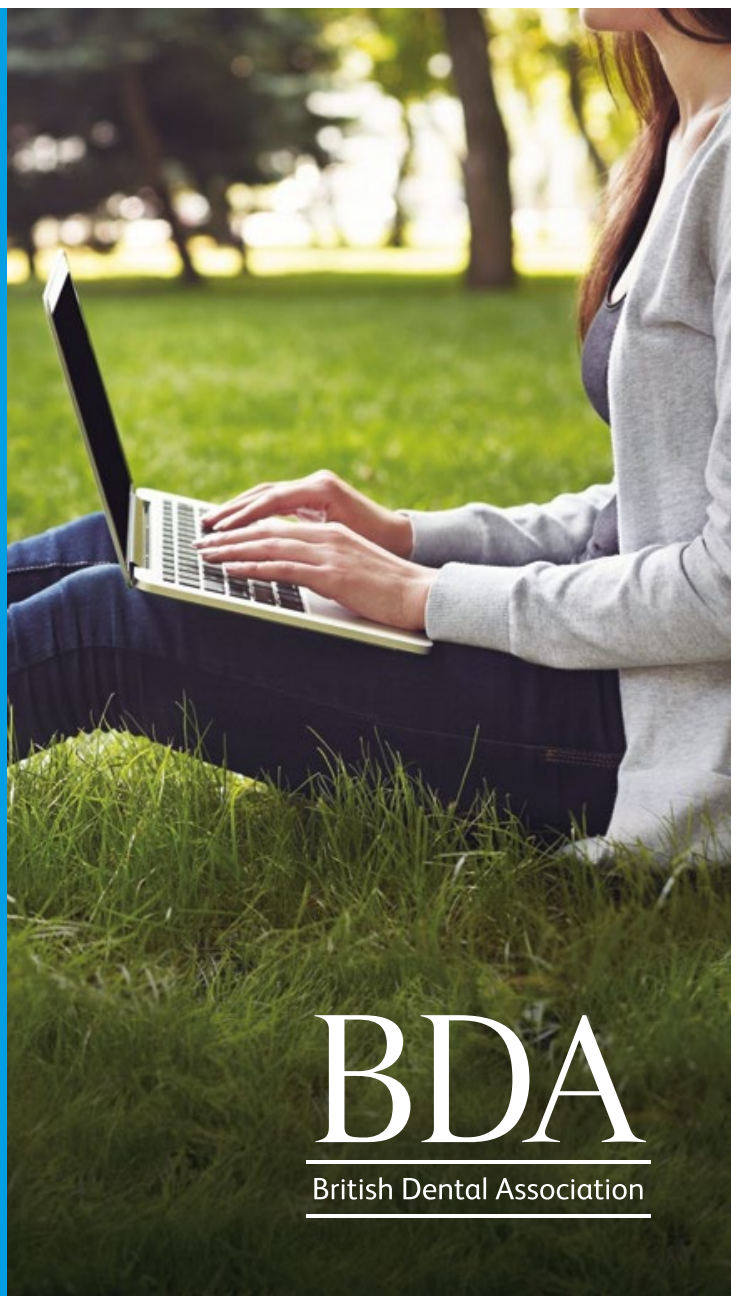

